\title{
VOLTAGE DEGRADATION MODEL OF THIN FILM CAPACITORS
}

\author{
T.M. BERLICKI \\ Technical University, Wroclaw, Poland \\ (Received November 1. 1983; in final form August 5, 1984)
}

\begin{abstract}
A degradation model of thin film capacitors is presented. This model takes into consideration that: (a) the damage rate $d D / d t$ is a function of the damage value $D$, and (b) the critical damage $D_{c}$ is a function of working voltage. On the base of this model, the short term breakdown voltage and its distribution is defined. The experimental data presented conforms with the described model.
\end{abstract}

\section{INTRODUCTION}

Usually in considering the reliability of capacitors the life time in the form of a power law ${ }^{1,2,3}$

$\tau=\frac{\mathrm{B}_{1}}{\mathrm{~V}^{\mathbf{n}}}$

or an exponential law $w^{3,4,5,6}$

$\tau=\mathrm{B}_{2} \exp (-\mathrm{aV})$

is assumed. In the above relations, $\tau$ is the life time, $V$ is the working voltage, $B_{1}$, $B_{2}$, a are constants. The relations (1) and (2) result from following degradation model $^{1}$

$\frac{\mathrm{dD}}{\mathrm{dt}}=\mathrm{S}(\mathrm{V})$

where $\mathrm{D}$ is the damage, $\mathrm{S}(\mathrm{V})$ is the damage rate as a function of working voltage.

The parameter D is a critical parameter of the capacitor, which due to physical or chemical aging processes changes as a function of time. ${ }^{7,8}$ When the damage $D$ changes from its initial value $D_{o}$ to the critical value $D_{c}$, breakdown occurs. The value of the initial damage $D_{0}$ is a random variable and hence the life time and the breakdown voltage are random variables too. Typically for the breakdown voltage the Weibull type distribution is accepted ${ }^{1,9,10}$

$p\left(V_{b}\right)=1-\exp \left[-\left(\frac{V_{b}}{b_{1}}\right)^{\lambda}\right]$.

where $V_{b}$ is the breakdown voltage, $b_{1}, \lambda$ are the Weibull distribution parameters.

The relation (4) is defined for $V_{b}$ from 0 to $\infty$ but from the experimental data the breakdown voltage should be limited to 0 to $V_{b} \max . V_{b} \max$ is a maximum value of the breakdown voltage equal to the breakdown voltage of a defect-free capacitor. If $D_{o}=D_{c}$, then the life time is equal to zero. This case takes place, when the working voltage is equal to the breakdown voltage. The above 
observations do not conform with relations (1), (2) and (4). Hence a correction of that underlying model is needed. This is particularly important in the case, when the elements are tested by using the accelerated methods (step or ramp test). In these methods the capacitors are tested at voltages near the breakdown voltage, when the relations (1) and (2) are not correct For instance applying a linear voltage increase ${ }^{1}$

$\mathrm{V}_{\mathrm{br}}=\mathrm{Br}^{\underline{1}}$

where $\mathrm{V}_{\mathrm{br}}$ is the breakdown voltage for linear voltage increase, $\mathrm{r}$ is the rate of voltage increase, $B$ and $n$ are constants. From (5) one can find, that $V_{b r} \rightarrow \infty$ if $r \rightarrow \infty$ and this is not correct in a physical sense.

\section{THE DEGRADATION MODEL}

If one assumes, as $\operatorname{in}^{7,8}$ the degradation model in the form:

$\frac{\mathrm{dD}}{\mathrm{dt}}=\mathrm{S}(\mathrm{V}) \mathrm{K}(\mathrm{D})$

and that the function $\mathrm{K}(\mathrm{D})$ is in the form ${ }^{7}$

$K(D)=a_{1} D^{m}$

then the life time is given by:-

$\tau=\frac{1}{\mathrm{~S}(\mathrm{~V})} \int_{\mathrm{D}_{0}}^{\mathrm{D}_{\mathrm{c}}} \frac{\mathrm{dD}}{\mathrm{K}(\mathrm{D})}=\frac{1}{\mathrm{a}_{1}(\mathrm{~m}-1)} \overline{\mathrm{S}(\mathrm{V})}\left[\frac{1}{\mathrm{D}_{0}^{\mathrm{m}-1}}-\frac{1}{\mathrm{D}_{\mathrm{c}}^{\mathrm{m}-1}}\right]$

where $a_{1}$ and $m$ are constants.

The value of the critical damage is dependent on the working voltage. For the breakdown voltage, the value of initial damage $D_{0}$ is already a critical value $D_{o}=D_{c}$. The value of $D_{c}$ increases as the working voltage is decreased. If we assume that

$D_{c}=d_{c}\left(\frac{V_{b \max }}{V}-1\right)^{k}$

where $d_{c}$ and $k$ are constants, then

$\tau=\mathrm{b} \frac{\mathrm{d}_{\mathrm{c}}^{(\mathrm{m}-1)}\left(\frac{\mathrm{V}_{\mathrm{b} \max }}{\mathrm{V}}-1\right)^{\mathrm{k}_{\mathrm{l}}}-\mathrm{D}_{0}^{(m-1)}}{\mathrm{D}_{0}^{(m-1)}\left(\frac{\mathrm{V}_{\mathrm{b} \max }}{\mathrm{V}}-1\right)^{\mathrm{k}_{1}} \mathrm{~S}(\mathrm{~V})}$

where

$$
\mathrm{b}=\frac{1}{\mathrm{a}_{1}(\mathrm{~m}-1) \mathrm{d}_{\mathrm{c}}^{(m-1)}}, \mathrm{k}_{1}=\mathrm{k}(\mathrm{m}-1)
$$


If the function of $S(V)$ is given by (2) or (3) a relation for life time versus voltage may be obtained from (9).

In the above examples the initial damage and life time are the random variables. From (10) the life time can be defined, when fraction $\mathrm{W}$ of capacitors is broken [for $\mathrm{W}=50 \%$ the median life time is $-(\tau(50 \%)]$. From the value of $\mathrm{D}_{\mathrm{o}}$, the short term breakdown voltage can be derived from the value of $D_{0}$. This is the voltage at which the value of $\mathrm{D}_{\mathrm{o}}$ is critical, and now $\tau=\mathrm{O}$.

From (10)

$$
\mathrm{V}_{\mathrm{b}}=\mathrm{V}_{\mathrm{b} \max } \frac{\mathrm{d}_{\mathrm{c}}^{\mathrm{k}^{\overline{\mathrm{k}}}}}{\mathrm{D}_{0}{ }^{\frac{1}{\mathrm{k}^{2}}+d_{c}{ }^{\bar{k}}}}
$$

and hence

$$
\tau=b \frac{\left(\frac{V_{b \text { max }}}{V}-1\right)^{k_{1}}-\left(\frac{V_{b \text { max }}}{V_{b}}-1\right)^{k_{1}}}{\left(\frac{V_{b \text { max }}}{V_{b}}-1\right)^{k_{1}}\left(\frac{V_{b \text { max }}}{V}-1\right)^{k_{1}} S(V)}
$$

If $\mathrm{V}_{\mathrm{bmax}} \gg \mathrm{V}_{\mathrm{b}}$

$$
\tau=\mathrm{b} \mathrm{V}_{\mathrm{b} \max }{ }^{-\mathrm{k}_{1}}\left(\mathrm{~V}_{\mathrm{b}}^{\mathrm{k}_{1}}(50 \%)-\mathrm{V}^{\mathrm{k}_{1}}\right) \frac{1}{\mathrm{~S}(\mathrm{~V})}
$$

and the median

$$
\tau(50 \%)=\mathrm{b} \mathrm{V}_{\mathrm{b}}^{-\mathrm{k}_{1}}\left(\mathrm{~V}_{\mathrm{b}}^{\mathrm{k}_{1}}(50 \%)-\mathrm{V}^{\mathrm{k}_{1}} \frac{1}{\mathrm{~S}(\mathrm{~V})}\right.
$$

and if $\mathrm{V}_{\mathrm{b}} \gg \mathrm{V}$

$\tau=\mathrm{bV}_{\mathrm{b} \max }^{-\mathrm{k}_{1}} \mathrm{~V}_{\mathrm{b}}^{\mathrm{k}_{1}} \frac{1}{\mathrm{~S}(\mathrm{~V})}$

and for power or exponential relation of $S(V)$ we have (1) or (2) respectively.

Eq. (12) is a generalization of the relation (1) or (2). The breakdown voltage $V_{b}$ is a theoretical value. The breakdown voltage is measured at the increasing voltage and during the measurement the coefficient $\mathrm{D}$ changes.

If a linear voltage increase is assumed

$$
\mathrm{V}=\mathrm{rt}
$$

where $r$ is a constant

then

$$
\int_{D_{0}}^{D_{c}} \frac{d D}{K(D)}=\int_{0}^{\tau_{r}} S(r t) d t
$$

where $\tau_{\mathrm{r}}$ is the life time with the linear voltage increase. From (7) and (16):-

$\mathrm{b}\left[\left(\frac{\mathrm{V}_{\mathrm{b} \max }}{\mathrm{V}}-1\right)^{-\mathrm{k}_{\mathrm{i}}}-\left(\frac{\mathrm{V}_{\mathrm{b} \max }}{\mathrm{V}_{\mathrm{br}}}-1\right)^{-\mathrm{k}_{1}}\right]=\frac{1}{\mathrm{r}} \mathrm{G}\left(\mathrm{V}_{\mathrm{br}}\right)$ 
where

$G\left(V_{b r}\right)=\int_{0}^{V_{b r}} S(V) d V$

$\mathrm{V}_{\mathrm{br}}$ is the breakdown voltage for linear voltage increase. For a high rate of voltage increase

$\mathrm{V}_{\mathrm{br}} \cong \mathrm{V}_{\mathrm{b}}$

and for a low increase rate

$\mathrm{G}\left(\mathrm{V}_{\mathrm{br}}\right)=\mathrm{r} \mathrm{V}_{\mathrm{b}}^{\mathrm{k}_{1}}$

The probability $p\left(V_{b}\right)$, that the capacitor breaks at the votlage $V \leqslant V_{b}$ is defined by the capacitor area and the density of weak spots.

$\mathrm{p}\left(\mathrm{V}_{\mathrm{b}}\right)=1-\exp \left(-\mathrm{A} \gamma\left(\mathrm{V}_{\mathrm{b}}\right)\right)$

where $\mathrm{A}$ is a capacitor area, $\gamma\left(\mathrm{V}_{\mathrm{D}}\right)$ is the density of weak spots as a function of breakdown voltage.

If we assume that the following relation approximately holds

$\gamma\left(\mathrm{V}_{\mathrm{b}}\right)=\frac{\mathrm{M}}{\mathrm{D}_{0}{ }^{1}}$

where $M$ and 1 are constants and $V_{b}$ is a function of $D_{o}$ [eg. (11)] then

$\mathrm{p}\left(\mathrm{V}_{\mathrm{b}}\right)=1-\exp \left[-\mathrm{A} \frac{\mathrm{M}}{\mathrm{d}_{\mathrm{c}}{ }^{1}}\left(\frac{\mathrm{V}_{\mathrm{b} \max }}{\mathrm{V}_{\mathrm{b}}}-1\right)^{-\mathrm{k} 1}\right]$

If $\mathrm{V}_{\mathrm{b}} \max \geqslant \mathrm{V}_{\mathrm{b}}$, then (21) approaches the Weibull type relation.9,10

From (12) and (21) the life time distribution results. In particular if $\mathrm{V}_{\mathrm{b}}$ max $\gg \mathrm{V}_{\mathrm{b}}$ and $\mathrm{V}_{\mathrm{b}} \mathrm{k}_{1} \gg \mathrm{V}^{\mathrm{k}_{1}}$ a Weibull type distribution is obtained:-

$\mathrm{p}(\tau, \mathrm{V})=1-\exp \left[-\mathrm{A} \frac{\mathrm{C}}{\mathrm{d}_{\mathrm{c}}{ }^{1}}\left(\frac{\tau \mathrm{S}(\mathrm{V})}{\mathrm{b}}\right)^{\frac{1}{(\mathrm{~m}-1)}}\right]$

This degradation model is compatible with the physical model described in. ${ }^{11}$ It has been stated that a metallic spike is formed in the weak spot as a result of ionic current flow. The electric field at this spot is considerably higher than the average field as in the case of the edge effect. The rate of the spike height growth vs electric field is given by the approximate relation ${ }^{11}$ :-

$\frac{\mathrm{dh}}{\mathrm{dt}}=\mathrm{b}_{2} \mathrm{j}(\mathrm{E}) \mathrm{h}^{\beta}$

where $h$ is the height of the spike, $j(E)$ is the ionic current and $b_{2}$ is a constant. If it is assumed, that $\mathrm{D} \equiv \mathrm{h}$, then Eq. (23) is conformable to the Eqs. (6) and (7). The local field $E_{1}$ at the spike is

$\mathrm{E}_{1}=\mathrm{E}\left(1+\alpha \mathrm{h}^{\beta}\right)$ 
The growth of the metallic spike lasts until the local electric field exceed the critical value, $\mathrm{E}_{\mathrm{c}}$, and then

$\mathrm{E}_{\mathrm{c}}=\mathrm{E}\left(1+\alpha \mathrm{h}_{\mathrm{c}}^{\beta}\right)$

and for the initial value of $h_{0}$

$\mathrm{E}_{\mathrm{c}}=\mathrm{E}_{\mathrm{b}}\left(1+\alpha \mathrm{h}_{\mathrm{O}}^{\beta}\right)$

where $E=V / d, d$ is thickness of the dielectric, $E_{b}$ is a breakdown field $\left(E_{b}=V_{b} / d\right), h_{o}$, $\mathrm{h}_{\mathrm{c}}$ are the initial and critical value of the spike height respectively.

From (25) is

$h_{c}=\left[\frac{1}{\alpha}\left(\frac{E_{c}}{E}-1\right)\right]^{\frac{1}{\beta}}$

The above relation is identical to Eq. (9) if

$\frac{E_{c}}{E}=\frac{V_{b \max }}{V}$

\section{RESULTS OF THE MEASUREMENTS}

Thin film capacitors $\mathrm{Al}-\mathrm{Al}_{2} \mathrm{O}_{3}$ - metal were used in the epxeriments. The metallic layers were prepared by evaporation onto a Corning 7059 glass substrate. The $\mathrm{Al}_{2} \mathrm{O}_{3}$ layer was produced by anodic oxidation of aluminium in a solution of ammonium pentaborate in ethylene glycol. The thickness of the $\mathrm{Al}_{2} \mathrm{O}_{3}$ film was about $1400 \AA$. The breakdown was measured with a linear voltage increase. The dependence of the breakdown voltage $\mathrm{V}_{\mathrm{br}}$ on the rate of voltage increase is presented in Figure 1. An increase in the rate of voltage change above $1 \mathrm{Vs}^{-1}$ has

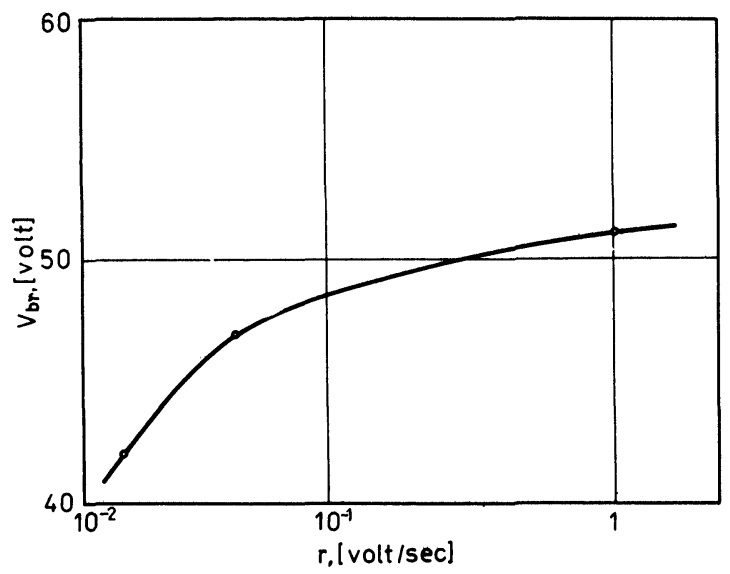

FIGURE 1 The dependence of the breakdown voltage vs the rate of voltage increase. 


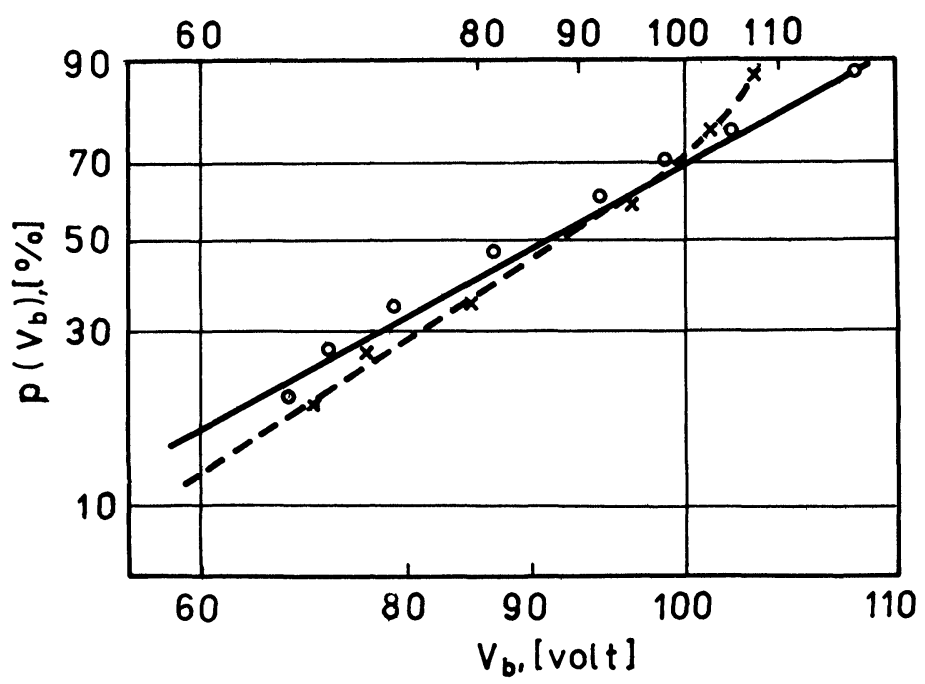

FIGURE 2 Probability of breakdown as a function of breakdown voltage; - $\mathrm{x}$ - in Weibull scale/upper scale/, - o - in propose scale/bottom scale/.

little influence on the breakdown voltage. The measurement data of the breakdown voltage distribution is shown in Figure 2, with a rate of voltage increase of $1 \mathrm{volt} / \mathrm{sec}$.

Conformity with relation (21) was verified by plotting the results with ordinates scaled: $\ln (-\ln (1-p))-\ln \left(V_{b \max } / V_{b}-1\right)$. It was assumed that $V_{b \max }=120$ volts. A straight line in the entire range of $\mathrm{V}_{\mathrm{b}}$ is obtained. If this data is plotted in typical Weibull scale $\left(\ln (-\ln (1-p))-\ln V_{b}\right)$ an aberration from straight line for voltage near $\mathrm{V}_{\mathrm{b} \text { max }}$ is noticed.

\section{CONCLUSION}

The present model of the degradation of capacitors is a correction to the known model. ${ }^{1}$ This correction gives a significant change in a dependence of the life time on the working voltage, when the voltage is near the breakdown voltage. If the voltage is low, and $\mathrm{V}_{\mathrm{b}} \gg \mathrm{V}$ the relation remains unchanged in comparison with (1) or (2). A similar situation occurs in the case of the breakdown voltage distribution. When the breakdown voltage is $\mathrm{V}_{\mathrm{b}} \ll \mathrm{V}_{\mathrm{b} \text { max }}$ the Weibull type of distribution is obtained, but at voltages near $V_{b \text { max }}$ the present model gives values closer to those observed. If the experimental data is presented on the scale $\ln (-\ln (1-p))-\ln V_{b}$, then at a breakdown voltage near the $\mathrm{V}_{\mathrm{b} \max }$ a deviation from a straight line is obtained. This means, that in this breakdown voltage range the experimental data do not conform with the Weibull distribution. In the case of the $\ln (-\ln (1-p))$ and $\ln \left(\mathrm{V}_{\mathrm{v} \max } / \mathrm{V}_{\mathrm{b}}-1\right)$ scale, as in Figure 2, a straight line in the entire range of $\mathrm{V}_{\mathrm{b}}$ is obtained. When the capacitors are tested by applying a ramp test, $V_{b r}$ increases asymptotically to $\mathrm{V}_{\mathrm{b}}$ as the rate of voltage increases.

This is in contrast to the known model (Eq. (5)), in which $V_{b r}$ increases up to ${ }^{\infty}$. For the experimental data presented in this paper, $V_{b r} \cong V_{b}$, when the $\mathrm{r}>1$ volts/sec. 
5. NOTATION

\begin{tabular}{|ll|}
\hline $\mathrm{V}$ & working voltage \\
$\tau$ & life time \\
$\mathrm{D}$ & damage \\
$\mathrm{D}_{\mathrm{o}}$ & initial volume of $\mathrm{D}$ \\
$\mathrm{D}_{\mathrm{c}}$ & critical volume of $\mathrm{D}$ \\
$\mathrm{S}(\mathrm{V})$ & domage rate \\
$\lambda, \mathrm{b}_{1}$ & Weibull distribution parameters \\
$\mathrm{V}_{\mathrm{b}}$ & short term breakdown voltage \\
$\mathrm{V}_{\mathrm{br}}$ & breakdown voltage for linear voltage increase \\
$\mathrm{r}$ & rate of voltage increase \\
$\mathrm{V}_{\mathrm{b} \text { max }}$ & maximum value of the breakdown voltage \\
$\mathrm{w}$ & fraction of broken capacitors \\
$\mathrm{B}_{1}, \mathrm{~B}_{2}, \mathrm{n}$, & $\mathrm{a}_{1}$, m, $\mathrm{d}_{\mathrm{c}}, \mathrm{k}, \mathrm{k}_{1}$ - constants \\
$\tau(50 \%)$ & medion life time \\
$\mathrm{t}$ & time \\
$\tau_{\mathrm{r}}$ & life time with the linear voltage increase \\
$\mathrm{A}$ & capacitor area \\
$\gamma\left(\mathrm{V}_{\mathrm{b}}\right)$ & density of weak spots \\
$\mathrm{M}, 1, \mathrm{C}$ & constants \\
$\mathrm{p}$ & probability of breakdown \\
$\mathrm{j}(\mathrm{E})$ & ionic current \\
$\mathrm{h}$ & height of the spike \\
$\mathrm{E}$ & electric field (E = V/d) \\
$\mathrm{E}_{\mathrm{l}}, \mathrm{E}_{\mathrm{c}}$ & local and critical electric field \\
$\mathrm{h}_{\mathrm{o}}, \mathrm{h}_{\mathrm{c}}$ & initial and critical value of the spike height \\
$\mathrm{d}$ & thickness of dielectric \\
$\mathrm{b}_{2}, \alpha, \beta$ & constants \\
&
\end{tabular}

\section{REFERENCES}

1. H.S. Endicott, B.D. Hatch, R.G. Sohmer, "Application of the Eyering model to capacitor aging data" IEEE Trans. Component Parts. CP-12, 34-41 (1965).

2. M.M. Drygen, "Design for reliability" Microelectron Reliab, 15, no 5, 399-436 (1976).

3. E. Loh, "Development of model for voltage degradation of various dielectric materials" IEEE Trans. Compon., Hybrids and Manuf., Technol. 4, no 4, 536-544 (1981). 
4. P. Salomon, M. Klein, M. Albert, "A statistical model for step and ramp voltage breakdown tests in thin insulators" Thin Solid Films 35, 321-326 (1976).

5. M. Shatzlees, M. Av-Ron, "Statistics of breakdown" IBM J. Res. Develop. 25, no 3, 167-175 (1981).

6. E.S. Anolick., G.R. Nelson, "Low - Field time dependent dielectric integrity" IEEE Trans., Reliability, R-29, no 3 217-221 (1980).

7. G. Bosch, "Model for failure rate curves" Microelectron Reliab, 19, 4, 371-375 (1979).

8. R. Viertel, "A note on a lifetime model" Microelectron Reliab. 21, 3, 745-748 (1981).

9. K. Kristiansen, "A statistical approach to the analysis of dielectric breakdown strength of thin insulating films" Vacuum, 27, no 4, 227-233 (1977).

10. T. Berlicki, "The influence of the area of a thin film capacitor on the breakdown voltage" Electrocomponent Science and Technology, 9, no 2, 111-114 (1981).

11. K.M. Gundlach, P. Schnupp, "Ionenwanderung als Durchschlagmechanismus dunner Aluminiumoxyd-Schichten," Z. angew. Phys. 21, no 6, 468-474 (1966). 

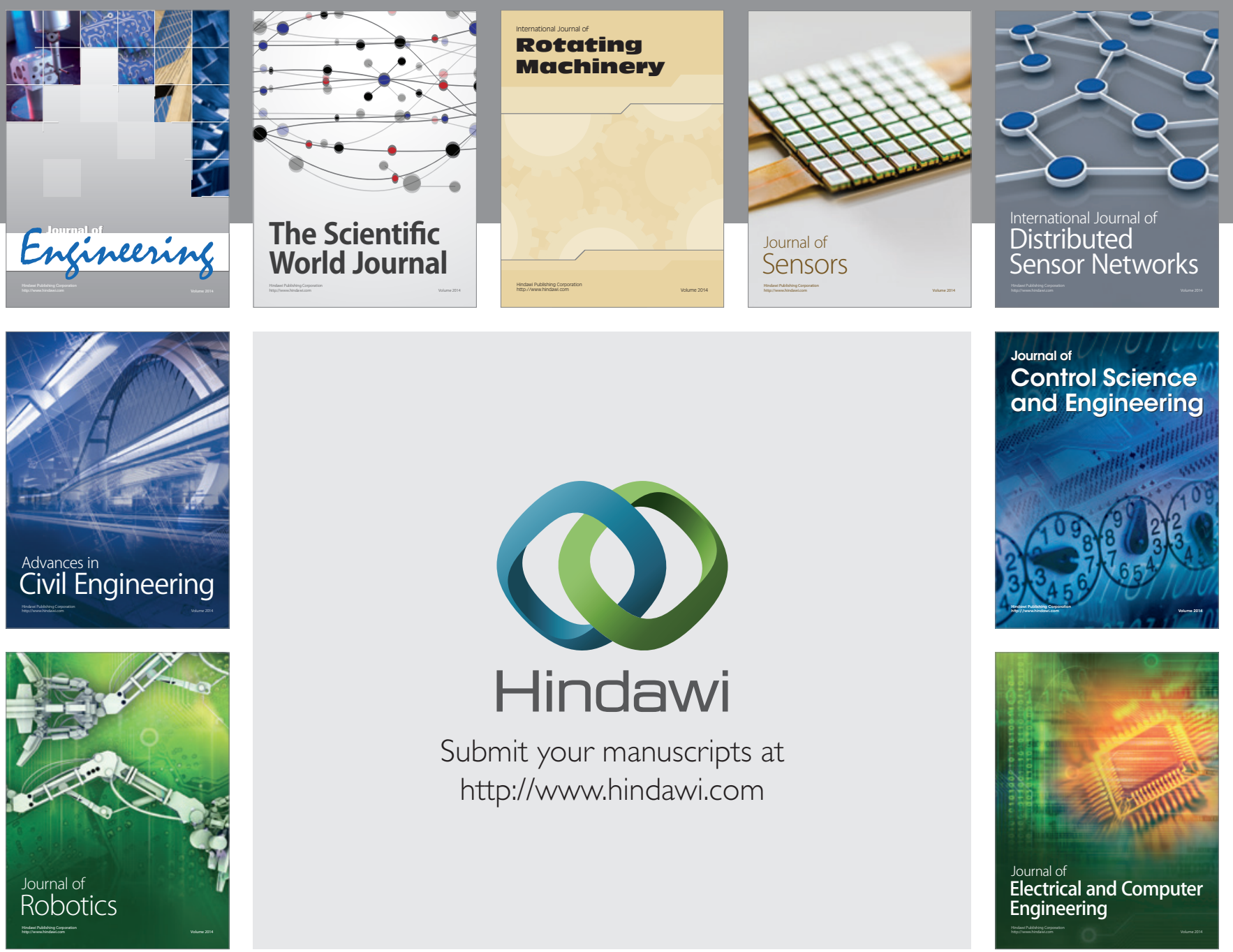

Submit your manuscripts at

http://www.hindawi.com
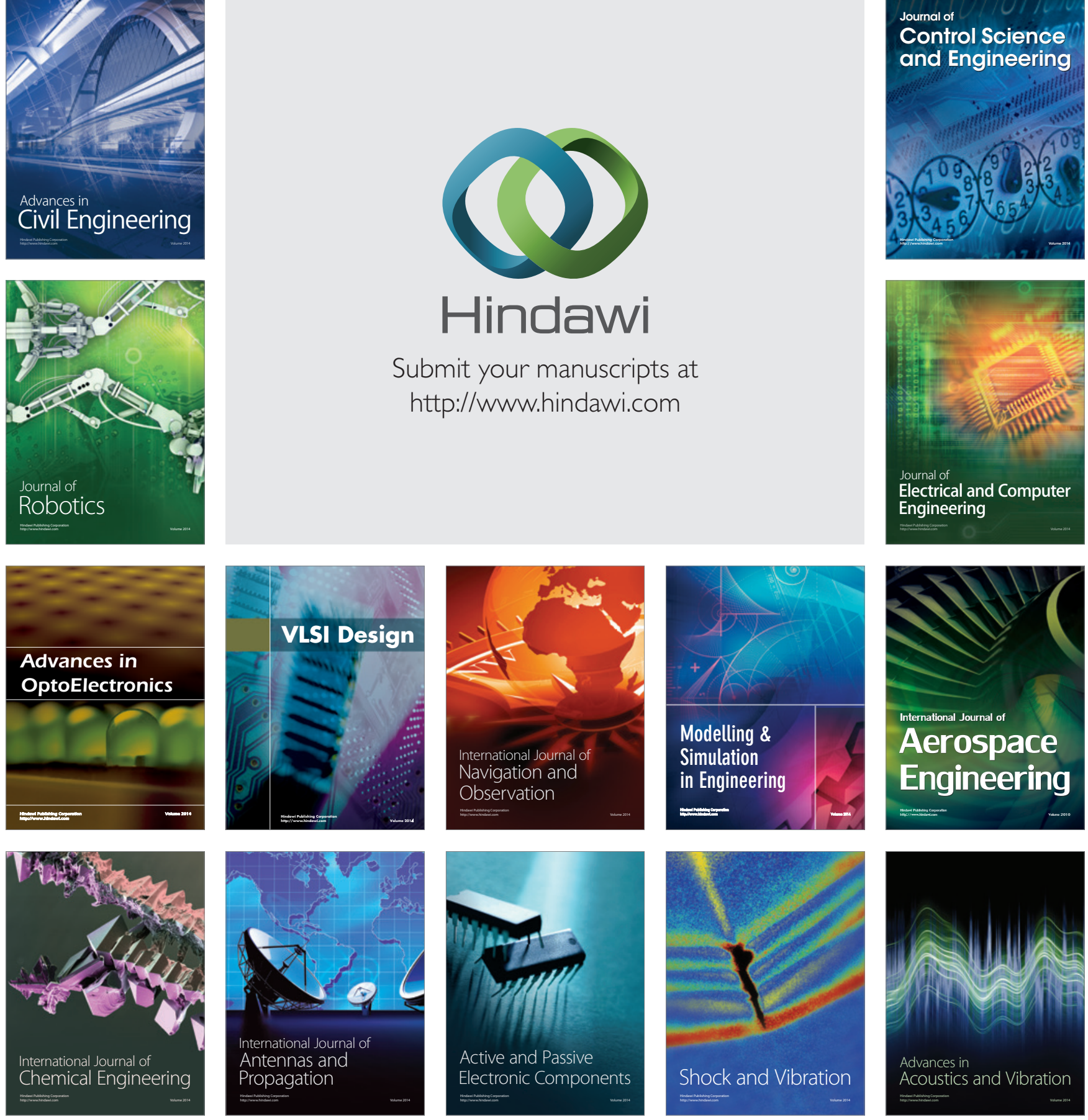